\title{
Primary pulmonary synovial sarcoma: A case with unique and impressive computed tomography findings
}

\author{
Jaspreet S Kambo MBBS ${ }^{1}$, Bonnie Richardson MD FRCPC ${ }^{1,2}$, Diana N Ionescu MD FRCPC FCAP ${ }^{3}$, \\ Tracy Tucker PhD FCCMG ${ }^{3}$, Greg Kraushaar MD FRCPC ${ }^{2,4}$
}

\begin{abstract}
JS Kambo, B Richardson, DN Ionescu, T Tucker, G Kraushaar. Primary pulmonary synovial sarcoma: A case with unique and impressive computed tomography findings. Can Respir J 2015;22(1):e1-e3.

Primary pulmonary synovial sarcoma (PPSS) is a rare malignancy. Its etiology, imaging features and optimal treatment are not well understood. Pulmonary pseudoaneurysms and lymphadenopathy are rare complications of synovial sarcomas. A 40-year-old woman with mild hemoptysis and thoracic back pain underwent a computed tomography scan that revealed multiple pulmonary lesions, paraesophageal lymphadenopathy and incidental bilateral pulmonary emboli. A diagnosis of PPSS was made through the identification of an SS18 translocation by fluorescence in situ hybridization. She was started on adriamycin, ifosfamide and mesna chemotherapy. Over the subsequent two months, she developed three pulmonary artery pseudoaneurysms, ultimately requiring endovascular coiling. Seven months after starting treatment, the patient was asymptomatic. The lesions and lymphadenopathy decreased in size. The present case highlights complications of a rare malignancy and demonstrates positive response to ifosfamide-based chemotherapy in the setting of PPSS.
\end{abstract}

Key Words: CT; Lymphadenopathy; PPSS; Pseudoaneurysm

Learning objectives

- To recognize synovial sarcoma (SS) as a rare cause of malignant pulmonary lesions.

- To recognize that primary pulmonary synovial sarcoma (PPSS) can present with lymphadenopathy and can be complicated by pulmonary artery pseudoaneurysms, which may require endovascular treatment to prevent life-threatening hemorrhage.

CanMeds competency: Medical Expert

Pretest

- What imaging findings and complications should be anticipated in PPSS?

- What is the cytogenetic hallmark of SS and an essential diagnostic tool?

\section{CASE PRESENTATION}

A 40-year-old woman was admitted to investigate a three-month history of cough associated with thoracic back pain. She denied any other symptoms. She had initially been treated for a presumed communityacquired pneumonia, although no investigations were undertaken at that time. Her medical history was unremarkable. She was on no medications, was a nonsmoker with no significant environmental/ occupational exposures and had no relevant family history. Physical examination revealed increased tactile fremitus and percussion dullness in the left upper zone, but was otherwise unremarkable.

Chest $\mathrm{x}$-ray revealed opacification of the left upper lobe consistent with infiltrative tumour and associated atelectasis. There were

\section{Le synovialosarcome pulmonaire primitif : un cas aux résultats de tomodensitométrie uniques et impressionnants}

Le synovialosarcome pulmonaire primitif (SSPP) est un cancer rare. On connaîten mal l'étiologie, les caractéristiques à l'imagerie et le traitement optimal. Les pseudo-anévrismes et les lymphadénopathies en sont de rares complications. Une femme de 40 ans présentant une hémoptysie bénigne et des dorsalgies a subi une tomodensitométrie qui a révélé de multiples lésions pulmonaires, une lymphadénopathie paraœsophagienne et une embolie pulmonaire bilatérale accessoire. Le dépistage d'une translocation SS18 par hybridation in situ en fluorescence a permis de diagnostiquer la SSPP. La femme a reçu une chimiothérapie à l'adriamycine, à l'ifosfamide et au mesna. Au cours des deux mois suivants, elle a fait trois pseudo-anévrismes pulmonaires, qui ont donné lieu à l'installation d'une spire endovasculaire. Sept mois après le début du traitement, la patiente était asymptomatique. Les lésions et la lymphadénopathie avaient diminué de volume. Le présent cas fait ressortir les complications d'un cancer rare et démontre la réponse positive de la chimiothérapie du SSPP à l'ifosfamide.

bilateral lung nodules and a small left apical pneumothorax. Chest computed tomography $(\mathrm{CT})$ revealed a large $(8.5 \mathrm{~cm}$ transverse $\times$ $10 \mathrm{~cm}$ anterior-posterior $\times 14 \mathrm{~cm}$ craniocaudal) soft-tissue mass centred in the left upper lobe and bulging into the major fissure (Figure 1). It encased the left pulmonary artery, left superior pulmonary vein and left upper lobe bronchus. Multiple bilateral pulmonary nodules of various sizes and a paraesophageal lymph node conglomerate mass measuring $3.7 \mathrm{~cm} \times 3.5 \mathrm{~cm}$ were consistent with metastatic disease. The patient had a saddle pulmonary embolism (PE) with multiple emboli observed throughout both lungs (Figure 1). There was a small left pleural effusion. CT scan of head, abdomen and pelvis revealed no other areas of involvement.

CT-guided core needle biopsy of the left upper lobe mass revealed a poorly differentiated biphasic neoplasm, which immunophenotypically lacked epithelial differentiation (including negative stains for keratin cocktail, EMA and CK7). The tumour cells were positive for CAM5.2, CD99, beta catenin and c-myc, weakly positive for CD56 and PAX8, and negative for p63 (for squamous differentiation), synaptophysin, chromogranin (for neuroendocrine differentiation), TTF-1, Napsin A (for lung origin), CD34 (ruling out a vascular neoplasm) and S100 (making malignant melanoma unlikely). A Ki-67 test revealed a mitotic index of $80 \%$. This immunohistochemical profile was nonspecific, and the biphasic neoplasm identified on hematoxylin and eosin slides was suspicious for SS. Fluorescence in situ hybridization (FISH) analysis on 200 nuclei was performed using the SS18 (18q11.2) probe; 70\% of the nuclei showed the $t(X ; 18)$ (p11.2; 11.2$)$ rearrangement (Figure 2). FISH studies were correlated with the morphological pathology examination of the tumour and the final diagnosis was SS. 


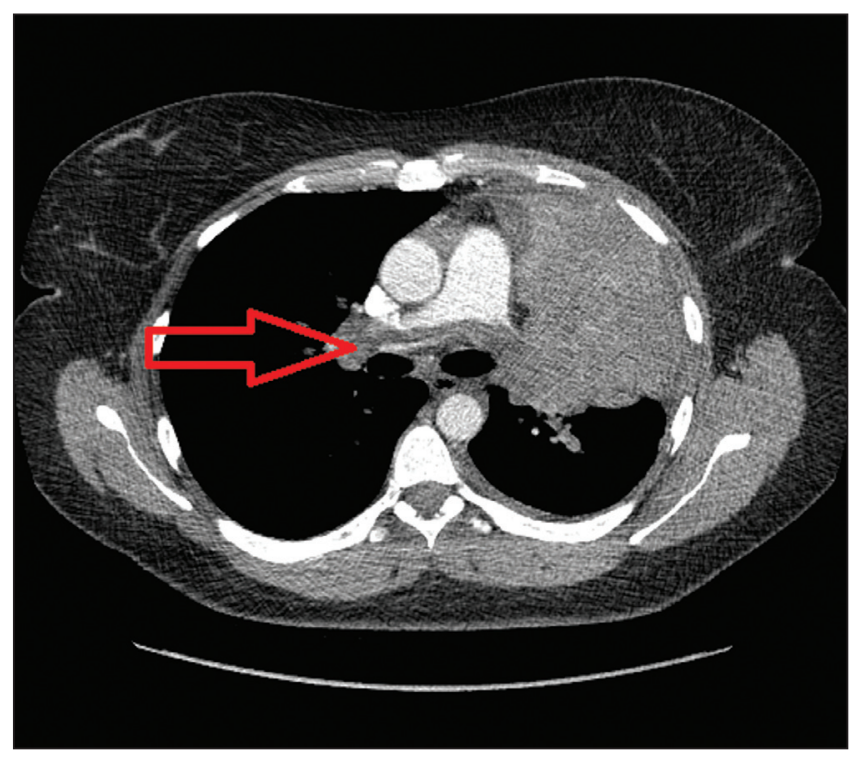

Figure 1) A large $(8.5 \mathrm{~cm} \times 10 \mathrm{~cm} \times 14 \mathrm{~cm})$ soft-tissue mass in the left upper lobe (arrow). It bulges into the major fissure with saddle pulmonary embolus

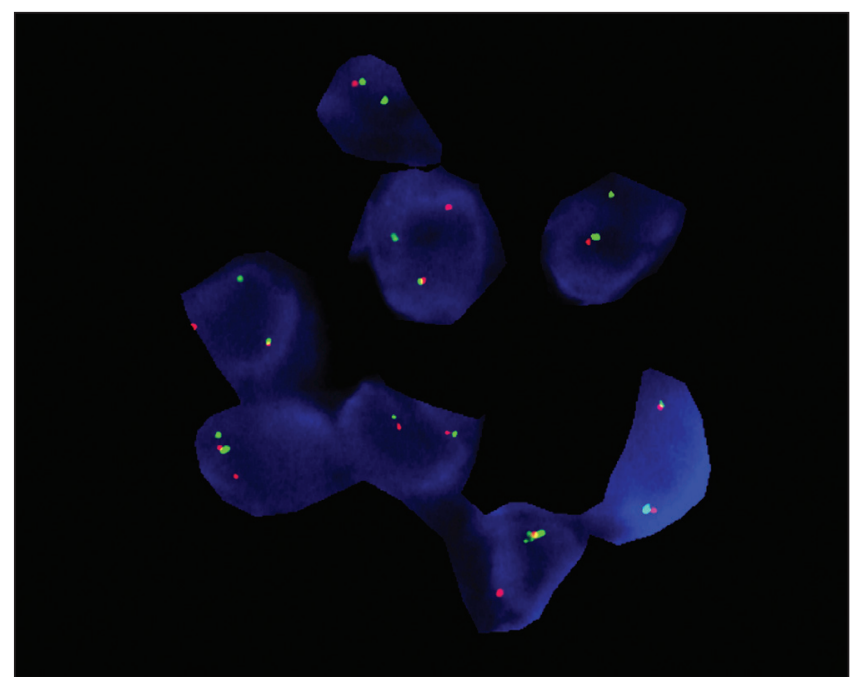

Figure 2) Fluorescence in situ hybridization studies demonstrating $t(X ; 18)$ (p11.2;q11.2) consistent with synovial sarcoma

The patient was started on palliative chemotherapy with adriamycin, ifosfamide and mesna and low-molecular-weight heparin for the PE. A repeat CT scan one month later revealed a drastic size increase in all lesions and lymph nodes; the left upper lobe lesion now measured $17 \mathrm{~cm} \times 11.7 \mathrm{~cm}$. The PEs had progressed despite optimal anticoagulation. There was also development of a left upper lobe pulmonary artery pseudoaneurysm $(4.5 \mathrm{~cm} \times 3.7 \mathrm{~cm})$. A CT scan one month later revealed progression of the aforementioned pseudoaneurysm $(4.9 \mathrm{~cm} \times 3.8 \mathrm{~cm})$ and two new pseudoaneurysms had developed on the left measuring $3 \mathrm{~cm} \times 2.2 \mathrm{~cm}$ and $2.1 \mathrm{~cm} \times 1.5 \mathrm{~cm}$. After discussion at multidisciplinary thoracic rounds, the consensus was that the patient would benefit from endovascular coiling of these pseudoaneurysms and the patient progressed to have embolization performed (Figure 3).

Four months after endovascular coiling, the patient has completed eight cycles of palliative chemotherapy with complete resolution of her symptoms. Surveillance CT imaging revealed that the lesions reduced in size, the left upper lobe lesion now measures $5.6 \mathrm{~cm}$ transverse $\times 4.4 \mathrm{~cm}$ anterior-posterior. The pseudoaneurysms show no enhancement. She is scheduled to continue chemotherapy until radiological resolution of the tumour.

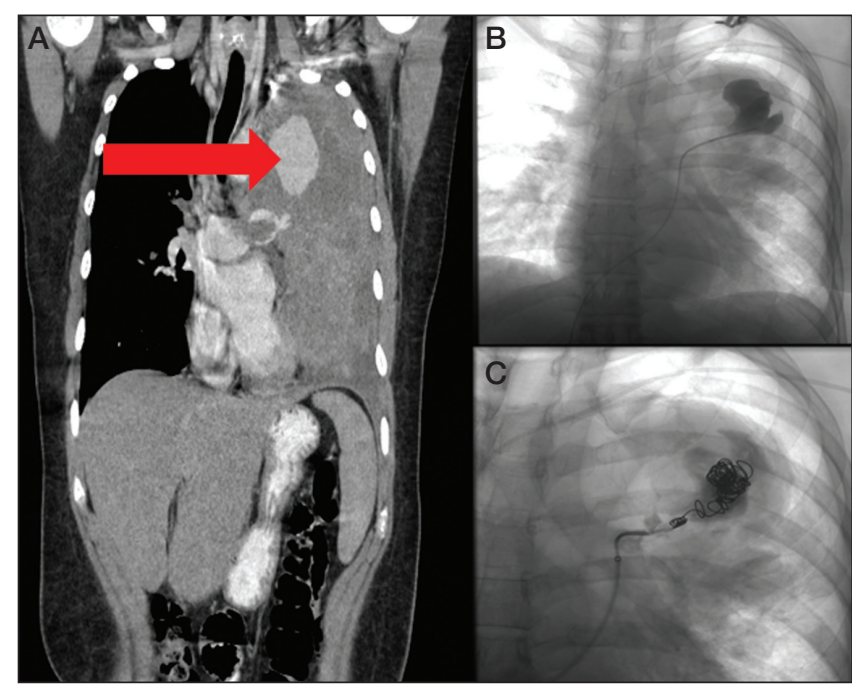

Figure 3) Follow-up computed tomography scan demonstrating progression of tumour and large pulmonary artery pseudoaneurysm (arrow) (A). Digitial subtraction angiographic images of the dominant pseudoaneurysm pre-and postcoiling ( $\mathbf{B}$ and $\mathbf{C}$, respectively)

\section{DISCUSSION}

A sarcoma is a malignant tumour of mesenchymal origin that accounts for $1 \%$ of adult malignancies. An SS is a tumour that histologically resembles a sarcoma; however, its cell of origin remains unclear. More than $75 \%$ of SS occur before 50 years of age and there is no sex bias. SS is a morphologically, clinically and genetically distinct entity that accounts for $5 \%$ to $10 \%$ of all soft tissue sarcomas and occurs mainly in a juxta-articular location in the deep soft tissues of the lower and upper extremities. Unusual sites of involvement include the kidney, adrenal gland, retroperitoneum, lung, mediastinum, bone and nervous system (1). The $t(X ; 18)(p 11.2 ; q 11.2)$ is the cytogenetic hallmark of SS and is present in $>90 \%$ of the cases. It produces three types of fusion genes formed in part by SS18 from chromosome 18 and by SSX1, SSX2 or, rarely, SSX4 from the X chromosome (2).

SS are often only noticed when $>5 \mathrm{~cm}$, depending on site. They have a tendency to recur and metastasize and, in many cases, even $>5$ years after diagnosis (3). Risk factors are not established, although there are case reports of an association with radiation exposure (4). Symptoms of PPSS are nonspecific but may include cough and chest pain (2).

Typical CT findings are a well-defined mass in the upper lobes with patchy low density, no lymphadenopathy and neurovascular/chest wall invasion $(2,5)$. The present case is unique because it demonstrates significant lymphadenopathy and multiple metastatic lesions confined to the lungs in a patient with PPSS. Furthermore, the development of pulmonary artery pseudoaneurysms is a rare but important complication that has been described in the setting of metastatic SS (6).

Standard treatment for metastatic SS is ifosfamide-based chemotherapy, regardless of anatomical location. Stereotactic body radiation therapy has been described as efficacious for local control of metastatic pulmonary lesions; however, its utility in primary pulmonary lesions lesions is poor (7). In this case, the widespread disease within the lungs resulted in the decision for chemotherapy alone. Even with multidrug regimens, the response rate of soft tissue sarcomas is 30\%, with progression-free survival of eight months (8).

PPSS is a rare malignant lesion of mesenchymal cells within the lungs. In the presence of the $t(X ; 18)(p 11.2 ; q 11.2)$ translocation according to FISH, the main differential diagnosis of PPSS is metastatic SS to the lungs, which can be ruled out by physical examination and radiological examinations. Here, we present an interesting case of PPSS in a young woman with no obvious risk factors. The CT findings were impressive, showing lymphadenopathy, invasion of 
cardiovascular and respiratory structures, and widespread metastases within the thorax. The patient had 'incidentally' detected bilateral $\mathrm{PE}$ at the time of CT diagnosis. Her treatment course was complicated by the development of multiple pulmonary arterial pseudoaneurysms, which has rarely been reported in cases of metastatic pulmonary sarcomas. Arterial embolization is the treatment of choice (6), although success rates in the setting are undetermined.

\section{Post-test}

- What imaging findings and complications should be anticipated in PPSS?

PPSS presents with large, patchy low-density lesions that may suggest lymphadenopathy and vascular involvement. Complications include pulmonary artery pseudoaneurysms, $\mathrm{PE}$ and pneumothroaces.

- What is the cytogenetic hallmark of SS and an essential diagnostic tool?

The $t(X ; 18)(p 11.2 ; q 11.2)$ is the cytogenetic hallmark of SS and is present in $>90 \%$ of cases.

\section{REFERENCES}

1. Suurmeijer AJ, de Brujin DR, Guerts van Kessel A, Miettinen MM, eds. Chapter 12: Synovial sarcoma. In: World Health Organization Classification of Tumors. Pathology and Genetics of Tumours of Soft Tissue and Bone. Lyon: IARC Press, 2012:213-5.

2. Sandberg AA, Bridge JA. Updates on the cytogenetics and tissue tumors. Synovial sarcoma. Cancer Genet Cytogenet 2002;133:1-23.

3. Krieg AH, Hefti F, Speth BM, et al. Synovial sarcomas usually metastasize after $>5$ years: A multicenter retrospective analysis with minimum follow-up of 10 years for survivors. Ann Oncol 2011;22:458-67

4. Vora A, Schneider B. Synovial sarcoma of the lung in a patient who received radioactive iodine therapy for thyroid cancer. Thyroid 2013;23:371-5

5. Zhang WD, Guan YB, Chen YF, Li CX. CT imaging of primary pleuropulmonary synovial sarcoma. Clin Radiol 2012;67:884-8.

6. Agarwal PP, Dennie CJ, Marzinger FR, Peterson RA, Seely JM. Pulmonary artery pseudoaneurysm secondary to metastatic angiosarcoma. Thorax 2006;61:366.

7. Dhakal S, Corbin KS, Milano MT, et al. Stereotactic body radiotherapy for pulmonary metastases from soft-tissue sarcomas: Excellent local lesion control and improved patients survival. Int J Radiat Oncol Biol Phys 2012;82:940-5.

8. Le Cesne A, Judson I, Crowther D, et al. Randomized phase III study comparing conventional-dose doxorubicin plus ifosfamide versus high-dose doxorubicin plus ifosfamide plus recombinant human granulocyte-macrophage colony-stimulating factor in advanced soft tissue sarcomas: A Trial of the European Organization for Research and Treatment of Cancer/Soft Tissue and Bone Sarcoma Group. J Clin Oncol 2000;18:2676-84. 


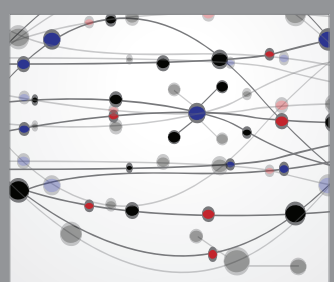

The Scientific World Journal
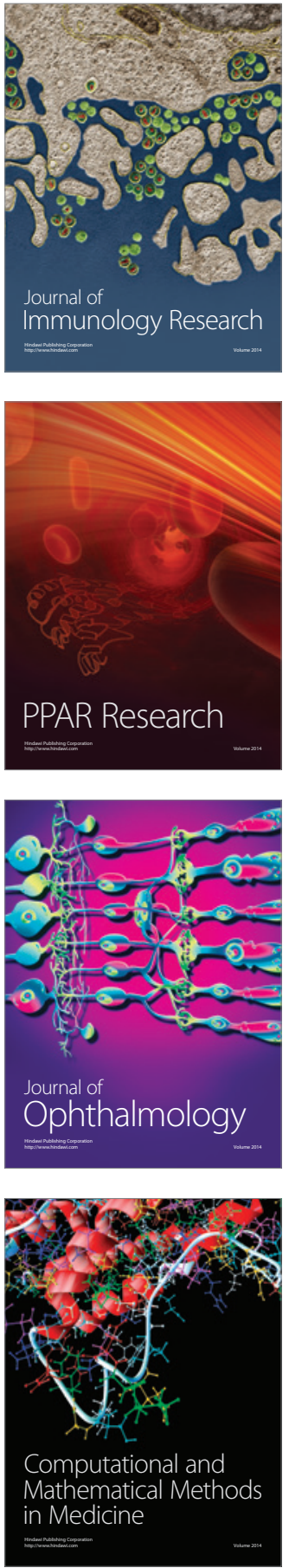

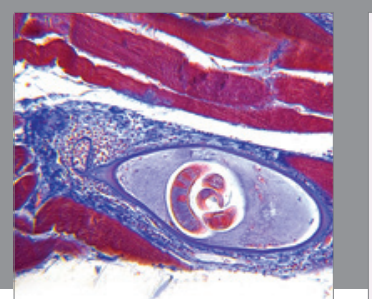

Gastroenterology Research and Practice

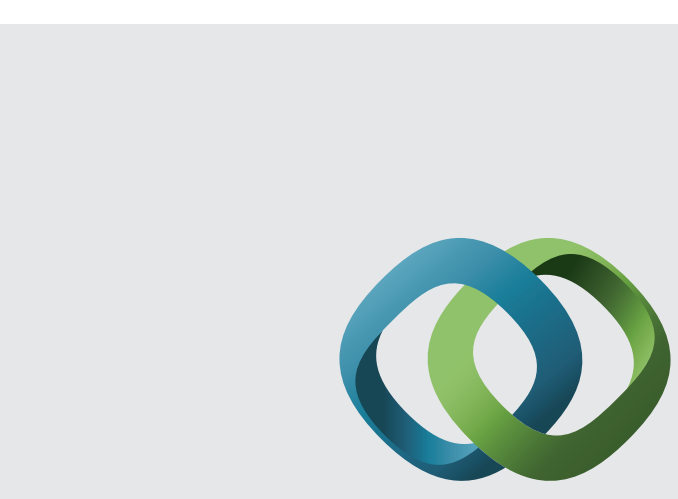

\section{Hindawi}

Submit your manuscripts at

http://www.hindawi.com
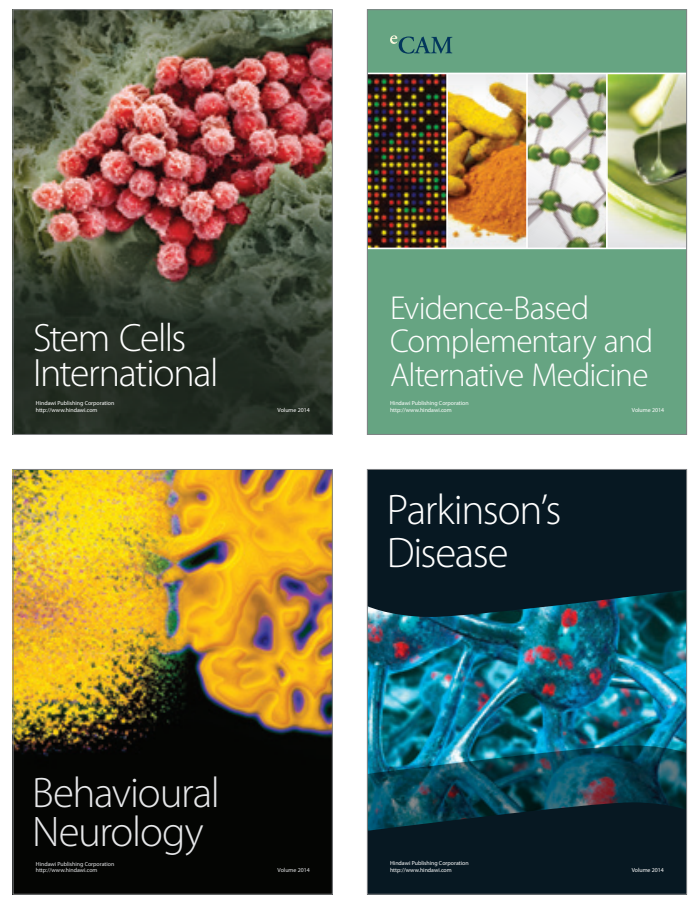
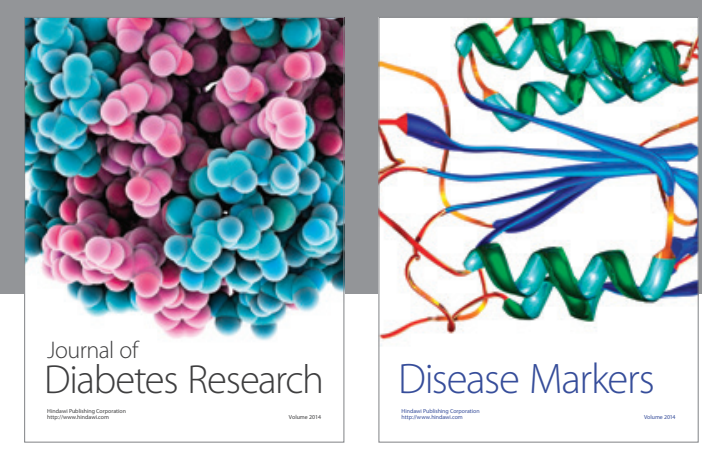

Disease Markers
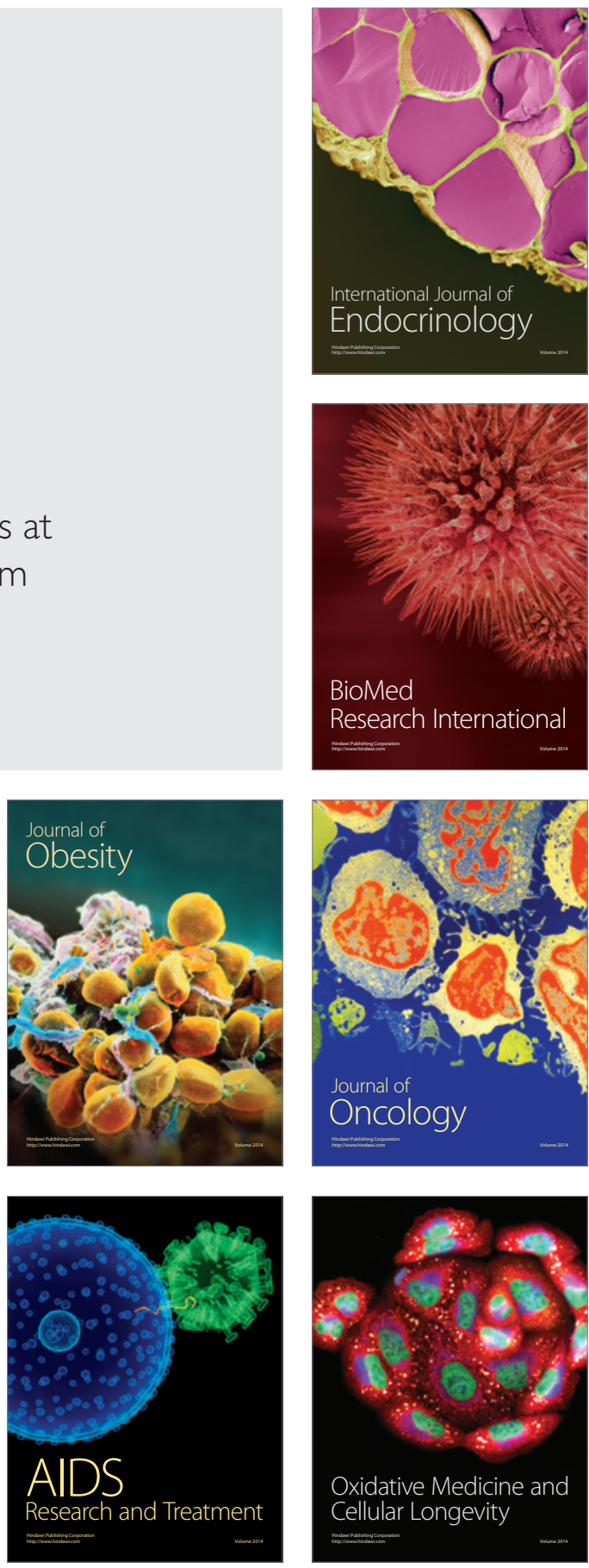